IRA-International Journal of Management \& Social Sciences

ISSN 2455-2267; Vol.04, Issue 02 (2016)

Pg. no. 314-323

Institute of Research Advances

http://research-advances.org/index.php/RAJMSS



\title{
An Ultrasound Study of Coarticulatory Resistance and Coarticulatory Aggression
}

\author{
${ }^{1}$ Irfana, $\mathbf{M}$ (Corresponding author) \\ Junior Research Fellow \\ Department of Speech Language Sciences \\ All India Institute of Speech and Hearing \\ Manasagangothri, Mysore -570006, India. \\ ${ }^{2}$ Sreedevi, N \\ Reader in Speech Sciences \\ Department of Clinical Services \\ All India Institute of Speech and Hearing \\ Manasagangothri, Mysore -570006, India.
}

Type of Review: Peer Review

DOI: http://dx.doi.org/10.21013/jmss.v4.n2.p2

\section{How to cite this paper:}

Irfana, M., \& Sreedevi, N. (2016). An Ultrasound Study of Coarticulatory Resistance and Coarticulatory Aggression. IRA-International Journal of Management \& Social Sciences (ISSN 2455-2267), 4(2), 314-323. doi:http://dx.doi.org/10.21013/jmss.v4.n2.p2

(C) Institute of Research Advances

\section{(cc) EY-No}

This work is licensed under a Creative Commons Attribution-Non Commercial 4.0 International License subject to proper citation to the publication source of the work.

Disclaimer: The scholarly papers as reviewed and published by the Institute of Research Advances (IRA) are the views and opinions of their respective authors and are not the views or opinions of the IRA. The IRA disclaims of any harm or loss caused due to the published content to any party. 
coarticulatory sensitivity of the consonants in VCV sequences (V-to-C effect) varies inversely with the strength of the consonantal effects (C-to- $\mathrm{V}$ effects) and with the degree of articulatory constraint of the intervocalic consonant. Recasens and Espinosa (2009) revealed that coarticulatory aggressiveness scale decreases in the progression from lingual fricatives, alveolopalatals, velars, labials, /n/, to a lesser extent, /// for consonants, high /i, u/ > low /a/ for vowels in Catalan. Based on tongue height, high vowels are more aggressive than low vowels (Recasens, 2012).

The present study intend to explore the coarticulatory resistance and aggression in Malayalam, a less explored language, across three places of articulation specifically voiced and unvoiced counterparts of dentals, retroflexes and velars with three cardinal vowels. Malayalam is one of the major Dravidian languages that is spoken in the south Indian state of Kerala. Like other languages of the sub-continent, it has complex set of place contrasts involving labials, alveolar, velars, dentals, palatals, and retroflexes (Asher \& Kumari, 1997).

Articulatory dynamics are different across these consonants and vowels. Production of retroflex consonant got particular interest because of its articulatory complexity and rarity across languages (Ladefoged \& Maddieson, 1996). It produces with higher articulatory constraint with sub-apical contact than other Dravidian language retroflexes (Sindusha, Irfana \& Sreedevi, 2014). The contact for the dental consonant is made with the moderately raised blade of the tongue, presumably at the alveolar ridge and the upper teeth. The shape of the tongue is overall lowered, and flat, with the posterior tongue body somewhat backed. The point of contact for the velar stop is presumably at the velum and the tongue body is strongly convex (Kochetov, Sreedevi, Kasim \& Manjula, 2014). The present study considered phonemes with different articulatory placement including phonemes more towards front i.e /i/ and dentals, back vowel $(/ \mathrm{u} /)$ and velars and phonemes more central position including vowel /a/ and retroflexes with the intention to explore the relation of coarticulation resistance and aggression with articulatory dynamics.

\section{Method}

Thirty native adult speakers of Malayalam served as subjects for this study. All of them were considered after oro motor examination and were excluded if identified with speech, language, hearing, or any cognitive deficits. The test material consisted of non-meaningful V1CV2 sequences with $C$ corresponding to voiced and unvoiced counterparts of dental stops $(/ \mathrm{t} /, / \mathrm{d} /)$ or retroflex stops $(/ \mathrm{t} /, / \mathrm{d} /)$ or velar stops $(/ \mathrm{k} /, / \mathrm{g} /)$ in the context of vowel V1 and V2, these were high front vowel /i/ or low central vowel /a/ or high back vowel /u/. Table 2.1 shows the test items. VCV were sequences embedded in a short carrier phrase (Now I will say CVCV).

Table 2.1: Stimuli list of V1CV2 sequences with consonant in 3 places of articulation in the context of vowel V1 and V2 (/a, i, u/).

\begin{tabular}{|c|c|c|c|c|c|c|}
\hline \multirow{3}{*}{ Vowels } & \multicolumn{6}{|c|}{ Places of articulation } \\
\hline & \multicolumn{2}{|c|}{ Dental } & \multicolumn{2}{|c|}{ Retroflex } & \multicolumn{2}{|l|}{ Velar } \\
\hline & Voiced & Unvoiced & Voiced & Unvoiced & Voiced & Unvoiced \\
\hline Low central & /adda/ & /atta/ & /adda/ & /atta/ & /agga/ & /akka/ \\
\hline High front & /idddi/ & /itti/ & /iddi/ & /itti/ & /iggi/ & /ikki/ \\
\hline High back & /uddu/ & /uttu/ & /uddu/ & /uttu/ & /uggu/ & /ukku/ \\
\hline
\end{tabular}

In the present study, articulatory movement data were obtained using the instrument Mindray ultrasound 6600. This system was connected to a PC installed with the software Articulate Assistant Advanced (AAA) ultrasound module Version 2.14 (Articulate Instrument, Wrench \& Scobbie, 2011) for the analysis with 60 frames per second. It was synchronized to the audio input with a sample rate of $22050 \mathrm{~Hz}$. Hardware pulse generated a tone frequency of $1000 \mathrm{~Hz}$ with beep length of 50 millisecond to accurate the synchronization. The transducer, a long-handled microconvex probe operating at $6.5 \mathrm{MHz}$, was placed beneath the chin of the participant with the support of stabilization headset (Articulate instrument, Scobbie, Wrench \& van der Linden, 2008). Each ultrasound frame 
stored by AAA system as a set of raw echo-pulse with a depth of $7 \mathrm{~mm}$ from which a standard two dimensional image was created. Figure 2.1 depicts the midsagittal ultrasound image of vowel /a/.

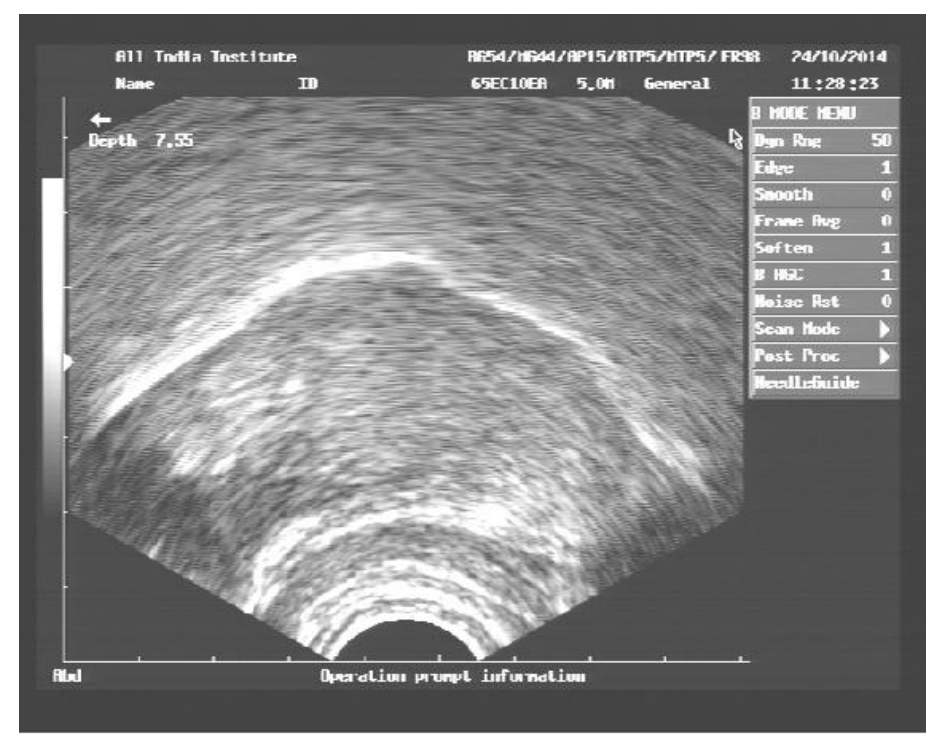

Figure 2.1. Midsagittal image of vowel /a/. The anterior tongue is towards the right side. (Note. Tongue image in Articulate Assistant Advanced, Phonology lab, Department of Speech Language Sciences, All India Institute of Speech and Hearing, Mysore).

2.1. Data collection: Participants were made to sit comfortably in a high back chair and the transducer probe was placed beneath the chin smeared with ultrasound transmission gel (Aquasonic 100) for better tongue imaging. The probe was fastened by stabilization headset (Articulate Assistant Advanced) to reduce the artifacts because of head movements. A headphone iball $i 333$ was used for recording the audio speech sample. Stimulus list was presented visually in grapheme mode to individual participant and 10 repetitions of each prompt were considered for further analysis. A total of 270 utterances were recorded from each participant including 10 repetitions of 9 target samples (3 same vowel contexts (V1CV1) * 9 consonants including both voiced and unvoiced counterparts= $27 * 10$ repetitions $=270)$. A grand total of 810 utterances $(30 * 270=8100)$ were recorded for the study.

2.2. Data Analysis: For analysis, semiautomatic contour plotting was considered in this study. Individual token splines for each consonant and vowel were used to create mean splines, based on means at 42 fan lines. Plotted contours were exported to workspace to find following parameters.

\subsubsection{Coarticulation resistance}

In VCV syllable, it is possible to find coarticulation resistance of consonants (CRC) and coarticulatory resistance of vowel (CRV). CRC is the ability of consonant to restrict the coarticulatory effect of preceding and/or following vowel. CRV is the vowel capacity to maintain its own characteristics. The formula used in the study was adapted from Zharkova (2007) to find the coarticulatory resistance.

\subsection{1.a) Coarticulation resistance of consonants (CRC)}

CRC was calculated in relation to both vowels from a VCV sequence where the calculations can also be performed in relation to V1 and V2 separately. CRC was found by using the formula:

$$
\mathrm{CRC}_{\mathrm{C}(\mathrm{V} 1-\mathrm{V} 2)}=\frac{(\mathrm{C}-\mathrm{V}) \quad \mathrm{X} 10}{\left(\mathrm{C}_{\mathrm{V} 1}-\mathrm{C}_{\mathrm{V} 2}\right)}
$$


In the above equation, the numerator " $\mathrm{C}-\mathrm{V}$ " indicates the averaged value of RMS of both $\mathrm{V} 1$ and $\mathrm{V} 2$ contexts. The denominator $\left(\mathrm{C}_{\mathrm{V} 1}-\mathrm{C}_{\mathrm{V} 2}\right)$ was obtained as RMS distance between tongue contours of $\mathrm{C}$ in different vowel contexts.

\subsection{1.b) Coarticulation resistance of preceding vowel (CRPV)}

CRPV was calculated in relation to different consonants from preceding vowel in VCV sequence. The RMS distances from the vowel to neighbouring consonant (V1-C and V2-C) are proportionate to the degree of CR of the vowel, i.e., the degree to which V retains its identity in a VCV sequence. The V1$\mathrm{C}$ and the V2-C, RMS distances were computed within token, separately for each of the tokens and for each of the 10 repetitions also. CRPV was found by using the formula:

$$
\mathrm{CRPV}_{\mathrm{V}_{(\mathrm{C} 1-\mathrm{C} 2)}=} \frac{(\mathrm{V}-\mathrm{C}) \quad \mathrm{X} 10}{\left(\sqrt{\mathrm{C}_{\mathrm{C} 1}-\mathrm{V}_{\mathrm{C} 2}}\right)}
$$

The numerator of the above equation, "V-C" indicates the averaged value of RMS of both contexts. The denominator $\left(\mathrm{V}_{\mathrm{C}_{1}}-\mathrm{V}_{\mathrm{C} 2}\right)$ was obtained as RMS distance between the mean tongue contours of $\mathrm{V}$ in different consonant contexts.

\subsection{1.c) Coarticulation resistance of following vowel (CRFV)}

CRFV was calculated in relation to different consonants from following vowel in VCV sequence. The analysis was similar as above described format. In this section following vowel was considered instead of preceding vowel to find the CRFV.

\section{Results}

\subsection{Tongue dynamics across places of articulation}

Figure 3.1-3.3 shows the average tongue contours of 30 subjects for each phoneme in VCV syllable. There was difference across tongue contours though the vowels were same in preceding and following context. General trend of fronting was observed when consonants neighboured with front vowel /i/. Both voiced and unvoiced counterparts of each place of articulation are discussed together since there is much variation across them in the tongue dynamics as seen from the images.

As seen figure 3.1, dental consonants were vulnerable and changed based on the vowels occurred with. It was evident that backing of posterior tongue body when they nearby with back vowel $/ \mathrm{u} / \mathrm{and}$ centralization of anterior tongue body when occurred with vowel /a/.
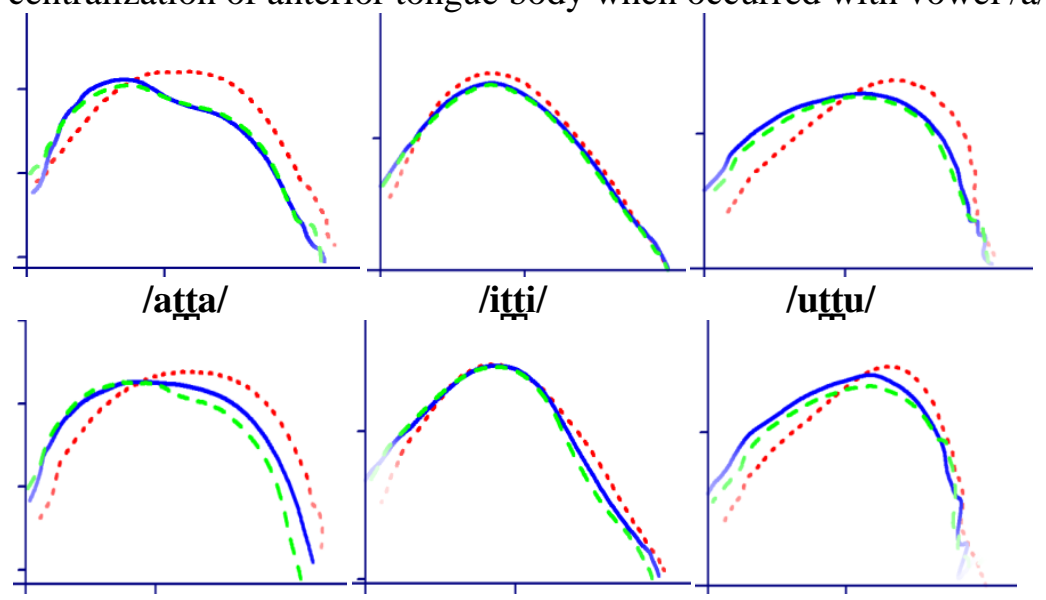

/adda/

/iddi/

/uddu/

Figure 3.1. Average tongue contours of 30 subjects- preceding vowel (red dotted line), consonant (blue solid line) and following vowel (green dashed line) for voiced and unvoiced counterparts of dental consonants across three vowel contexts. 
Contrast to dentals, retroflexes were influenced the vowels and changed the articulatory dynamics as observed in figure 3.2. Though there is some information loss of tongue tip curling, overall tongue shape of vowels were more as retroflexes especially back vowel /u/ and low central vowel /a/.

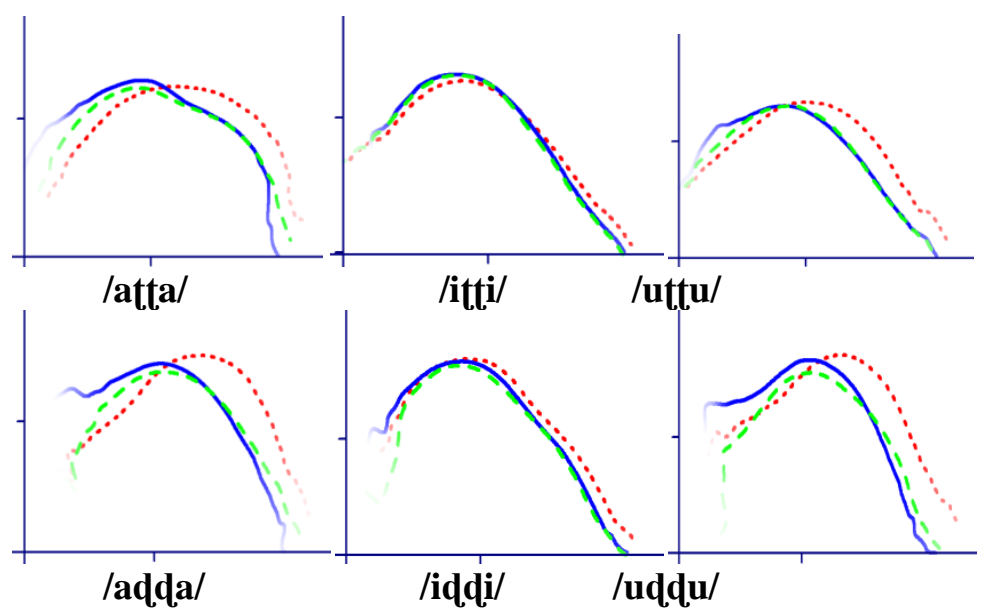

Figure 3.2. Average tongue contours of 30 subjects- preceding vowel (red dotted line), consonant (blue filled line) and following vowel (green dashed line) for voiced and unvoiced counterparts of retroflex consonants across three vowel contexts.

There were slight variations in articulatory position of vowels and velars. Velars were not always raise towards posterior with posterior tongue body. It was more of in between the articulatory position of velars and vowels. Especially when it occurred with front vowel /i/, there the tongue contour of velar consonant moved towards anterior position.



Figure 3.3. Average tongue contours of 30 subjects- preceding vowel (red dotted line), consonant (blue filled line) and following vowel (green dashed line) for voiced and unvoiced counterparts of velar consonants across three vowel contexts.

\subsection{Coarticulatory resistance of consonants}

Based on the equation, CRC calculated for each subject and mean and standard deviation of 30 subject depicted in Table 3.2. It is evident that the coarticulatory resistance is relatively higher when sequentially adjacent to vowels $/ \mathrm{a} / \mathrm{and} / \mathrm{u} /$ than other contexts. Interestingly, all the places of articulation including dental, retroflex, and velar stop consonants followed the same trend.

Friedman non-parametric tests were administered across consonants to analyse the coarticulatory resistance in each vowel context. Results showed that there was significant difference between the coarticulatory resistances of consonants in all the three vowel contexts $\left(\chi^{2}(5)=15.80, p<.001\right)$. 
Table 3.2: Mean and standard deviation of coarticulatory resistance of consonants of 30 subjects

\begin{tabular}{ccccccccc}
\hline CRC & Mean & SD & CRC & Mean & SD & CRC & Mean & SD \\
\hline CRCt $(a, \mathbf{i})$ & 12.27 & 4.88 & $\mathbf{C R C t}(\mathbf{a}, \mathbf{i})$ & 22.52 & 11.24 & $\mathbf{C R C k}(\mathbf{a}, \mathbf{i})$ & 15.42 & 5.85 \\
$\mathbf{C R C t}(\mathbf{a}, \mathbf{u})$ & 21.78 & 8.60 & $\mathbf{C R C t}(\mathbf{a}, \mathbf{u})$ & 36.01 & 21.04 & $\mathbf{C R C k}(\mathbf{a}, \mathbf{u})$ & 45.20 & 24.57 \\
$\mathbf{C R C t}(\mathbf{i}, \mathbf{u})$ & 15.68 & 7.56 & $\mathbf{C R C t}(\mathbf{i}, \mathbf{u})$ & 34.33 & 17.34 & $\mathbf{C R C k}(\mathbf{i}, \mathbf{u})$ & 14.78 & 7.78 \\
$\mathbf{C R C d}(\mathbf{a}, \mathbf{i})$ & 14.02 & 6.15 & $\mathbf{C R C d}(\mathbf{a}, \mathbf{i})$ & 26.97 & 12.26 & $\mathbf{C R C g}(\mathbf{a}, \mathbf{i})$ & 17.48 & 7.73 \\
$\mathbf{C R C d}(\mathbf{a}, \mathbf{u})$ & 24.72 & 10.70 & $\mathbf{C R C d}(\mathbf{a}, \mathbf{u})$ & 41.51 & 13.32 & $\mathbf{C R C g}(\mathbf{a}, \mathbf{u})$ & 44.74 & 20.4 \\
$\mathbf{C R C d}(\mathbf{i}, \mathbf{u})$ & 18.67 & 13.78 & $\mathbf{C R C d}(\mathbf{i}, \mathbf{u})$ & 32.71 & 14.05 & $\mathbf{C R C g}(\mathbf{i}, \mathbf{u})$ & 17.06 & 12.00 \\
\hline
\end{tabular}

Further, Wilcoxon Sign Rank test revealed similar pattern of coarticulatory resistance when the consonant was near to vowels $/ \mathrm{a} /$ and $/ \mathrm{i} /(|\mathrm{Z}|=4.271, \mathrm{p}=.010) ; / \mathrm{u} /$ and $/ \mathrm{i} /(|\mathrm{Z}|=2.098, \mathrm{p}=.036)$. Here, dental and velar consonants were significantly more influenced by adjacent vowels than retroflex consonants which were not different for both voiced and unvoiced counterparts. Particularly retroflex consonants set strong constraints on the tongue dorsum that limit the variation exerted by both preceding and following vowels, whereas, other consonants were influenced by adjacent segments.

Dental consonants were weak to exert coarticulation even when the vowels were $/ a /$ and $/ \mathrm{u} /$, while velars and retroflexes showed significantly higher magnitude of resistance $(\mathrm{p} \leq 0.001)$. Also, dentals permitted influence of all the three vowels when they preceded and followed in VCV segment, whereas, retroflex opposed the influence and maintained their own identity. Velars were flexible purely based on the context of vowel that were mutually compatible.

\subsection{Coarticulatory resistance of preceding vowel}

Table 3.2 depicts that the mean of coarticulatory resistance of preceding vowel was more for vowels /i/ and /u/ followed by /a/. Variability noticed was high for /a/ and relatively less for vowel /i/ indicating robust articulatory gesture.

Table 3.3: Mean and standard deviation of coarticulatory resistance of preceding vowel

\begin{tabular}{lcccccc}
\hline & \multicolumn{2}{c}{$\mathbf{t} \& \mathbf{d}$} & \multicolumn{2}{c}{$\mathbf{t} \& \mathbf{d}$} & \multicolumn{2}{c}{$\mathbf{k}$ \& $\mathbf{~}$} \\
\cline { 2 - 7 } Tokens & Mean & SD & Mean & SD & Mean & SD \\
\hline CRPV & 23.67 & 39.37 & 30.54 & 81.60 & 35.09 & 56.68 \\
CRPV & 49.17 & 18.63 & 79.74 & 21.48 & 69.59 & 23.62 \\
CRPV & 41.29 & 48.55 & 60.19 & 35.43 & 37.93 & 23.15 \\
\hline
\end{tabular}

Coarticulatory resistance by preceding vowels was analysed using Friedman test. Results showed significant difference of coarticulation resistance only in dental consonant contexts $\left(\chi^{2}(2)=20.89, p=\right.$ .001). Wilcoxon Sign Rank test revealed that vowel /a/ was having significantly less coarticulation resistance than $/ \mathrm{i} /$ and $/ \mathrm{u} /(|\mathrm{Z}|=2.887=15.23, \mathrm{p}=.004)$. This indicates that vowel $/ \mathrm{i} /$ and $/ \mathrm{u} / \mathrm{resisted}$ the influence of voiced and voiceless counterparts of dentals moreover similarly, whereas, vowel /a/ could not influence neighbouring consonants.

\subsection{Coarticulatory resistance of the following vowel}

Coarticulation resistance of following vowel /i/ was higher than /a/ and /u/ vowels. This was common across all the stop consonants considered in this study. Table 3.3 illustrates the mean and standard deviation of coarticulatory resistance of $/ \mathrm{a} /, \mathrm{i} /$, and $/ \mathrm{u} /$ in the following context. 
Table 3.4: Mean and standard deviation of coarticulatory resistance of following vowel

\begin{tabular}{lcccccc}
\hline & \multicolumn{2}{c}{$\mathbf{t} \& \mathbf{d}$} & \multicolumn{2}{c}{ t \& d } & \multicolumn{2}{c}{$\mathbf{k ~ \& ~} \mathbf{g}$} \\
\cline { 2 - 7 } Tokens & Mean & SD & Mean & SD & Mean & SD \\
\hline CRPV & 9.16 & 6.97 & 15.05 & 12.89 & 14.79 & 13.54 \\
CRPV & 13.87 & 4.67 & 19.05 & 8.47 & 17.16 & 10.07 \\
CRPV & 15.86 & 9.45 & 19.19 & 10.00 & 14.69 & 7.66 \\
\hline
\end{tabular}

The ability to retain the characteristics of following vowel was analysed using Friedman's test. There was significant effect in consonant context including dental $\left(\chi^{2}(2)=15.23, \mathrm{p}=.009\right)$ retroflex, and $\operatorname{velar}\left(\chi^{2}(2)=27.78, p=.000\right)$. Wilcoxon Sign Rank test was used to do pair wise comparison and the results showed the presence of stronger coarticulatory resistance of $/ \mathrm{i} /$ than $/ \mathrm{a} /(|\mathrm{Z}|=2.859, \mathrm{p}=.004)$ across three different places of articulation.

\section{Discussion}

The present study results revealed that the retroflex consonants $/ \mathrm{d} /$ and $/ \mathrm{t} /$ resisted coarticulatory effect significantly than other consonants especially in the context of $/ \mathrm{aCa} /, / \mathrm{iCi} /$, and $/ \mathrm{uCu} /$ respectively. Similar result was reported in another Dravidian language, Kannada study (Kochetov \& Sreedevi, 2013). A previous experiment (Sindusha, Irfana \& Sreedevi, 2013), reports that Malayalam retroflexes have more complicated tongue movement. Also, the angle between the slope of the surface of the anterior tongue body and the tongue blade is reduced indicating a greater degree of the tongue curling typical of a sub-apical post alveolar retroflex articulation.

Similarly, velar consonants highly resisted the influence when occurred in /a-a/ and /u-u/ contexts. This can be attributed to the presence of wider tongue dorsum contact area during the production of velars than dentals. Tongue dorsum constriction is very minimal in dental consonants where the tip of tongue touches the teeth to make obstruction rather than entire tongue body constriction.

To correlate, DAC model explains that the degree of coarticulation should vary with the constraints exerted upon the kinematics of different tongue constrictions. Thus, for instance, concluded that the place categories especially, retroflex consonants impose restrictions upon tongue activity to almost prevent V-to-V coarticulation from occurring. From this study, it is evident that coarticulatory resistance decreases progressively from retroflex $>$ velar $>$ dental. Though the production of retroflexes occurs as apical constriction rather than tongue dorsum constriction discussed in DAC model, the degree of constriction is more influential and this tongue tip constriction is more precise to make accurate angle of retroflection. Hence, this specific articulatory dynamics oppose the influence of other adjacent segments. Similarly, better coarticulatory resistance of velars than dentals provides reason to believe the notion of tongue dorsum constriction against palate. This suggests that the coarticulatory resistance scale is a valid criterion for consonant classification and also provides valuable information on spatio-temporal planning mechanisms underlying speaker's speech production.

Furthermore, results showed that there is significant difference in the coarticulatory resistance of vowels in preceding (V1) and following vowel (V2) contexts. Resistance declined progressively from high front vowel /i/ to high back vowel /u/ followed by low central vowel /a/. For coarticulatory resistance of preceding vowel, this pattern was seen only in the context of dental consonants. This might be because of the property of high coarticulatory resistance of the retroflex and velar consonants. However, resistance of vowel /i/ was obvious in all the three considered places of articulation than $/ \mathrm{u} /$ and $/ \mathrm{a} /$ in the following vowel context. This exemplifies that the high front vowel /i/ has the capacity to resist the influence of consonant in both preceding and following contexts. These results are in agreement with some of the previous studies where the vowel /i/ showed maximum coarticulatory resistance in English (Stevens \& House, 1963), Dutch (Pols, 1977), and Catalan (Recasens, 1985). 
Since the vowels behaved differently in preceding and following context, it is possible to deem the importance of phonetic place of a phoneme in a segment (Fowler \& Brancazio, 2000). Also, the present study indicated strong coarticulatory effect for high back vowel /u/ than low central vowel /a/. This is incongruent with previous studies (Perkell \& Nelson, 1985; Recasens \& Espinosa, 2009). This can be explained based on the property of vowel production, where both /a, $\mathrm{u} /$ are considered as back vowels in English, whereas, in Malayalam /a/ is low central vowel and possibility of variance is more compared to high back vowel /u/.

Coarticulatory aggressiveness is directly related to the resistance of the phoneme. Hence, it follows the same trend as explained in DAC model. Phonemes have raised tongue dorsum position and more constriction that show sheer antagonism against influence. Results reveal that the retroflexes in consonants and high front /i/ in vowel category spectacled maximum aggressiveness. Tongue dynamics of vowels were customized based on the neighbouring consonant. This was more evident when retroflexes were adjacent to vowels /a/ and /u/ (/atta/, /adda/, /uttu/, /uddu/). Retroflexes neighboured to other higher aggressive phoneme /i/ was interesting aspect of the study. Though direct parametric comparison is not applicable here, tongue contour of vowel/i/ was modified when it occurred in both preceding and following contexts. Tongue tip curling with wide angle of retroflection was observed during the production of $/ \mathrm{i} /$. Hence, the statement of opinion is that, coarticulatory aggressiveness is more for lingual consonants than vowels. Perhaps, tongue body constriction explains the same.

Articulatory dynamic properties of speech production categorise phonemes differently. Hence, it is not always possible to conclude coarticulation as language independent aspect. It is better to explain as combination of articulatory and language property. More crosslinguistic studies are required along this line to validate this notion.

\section{Acknowledgements}

We extend our sincere gratitude to Prof. S.R. Savithri, Director, All India Institute of Speech and Hearing for permitting us to carry out this study. We also thank all the participants of our study for their kind cooperation.

\section{References}

Articulate instrument, Scobbie, Wrench \& van der Linden, 2008

Articulate Instrument, Wrench A.A. \& Scobbie, J.M. (2011)

Bladon, R. A,. W. \& Nolan, F. J. (1977). A videofluorographic investigation of tip and blade alveolars in English. Journal of Phonetics, 5, 185-193.

Farnetani, A., \& Recasens, D. (2010). Differences in base of articulation for consonants among Catalan dialects, Phonetica, 67, 201-218.

Fowler, C. A. \& Saltzman, E. (1993). Coordination and coarticulation in speech production, Language and Speech, 36 (3), 171-195.

Hoole, P., Gfroerer, S ., \& Tillmann , H . G . (1990) Electromagnetic articulatography as a tool in the study of coarticulation, Forschungsberichte des Instituts flir Phonetik, Munich, 28, $107-122$.

Irfana, M. \& Sreedevi, N. (2016). Coarticulatory aggression and direction of coarticulation: an ultrasound study, International journal of innovative research and development, 5(5), 24-29.

Kochetov, A. \& Sreedevi, N. (2013). Vowel coarticulatory effect on Kannada retroflex stops. Proceedings of 10th International Seminar on Speech Production cologue, Germany.

Kouznetsov, V.B., \& Ott, A. (1987). Spectral properties of Russian stressed vowels in the context of palatalized and nonpalatalized consonants. XIth International Congress of Phonetic Sciences, 3, 117-120.

Kühnert, B. \& Nolan, F. (1999). The origin of coarticulation. In Coarticulation: Theory, Data and Techniques. W. J. Hardcastle and N. Newlett. Cambridge: Cambridge University 


\section{Press, 7-30.}

Pols, L C. W. (1977). Spectral analysis and identification of Dutch rowels in monosyllabic words. Soesterberg: Institute for Perception.

Recasens, D. (1985). Coarticulatory patterns and degrees of coarticulatory resistance in Catalan CV sequences. Language and Speech, 28, 97-114.

Recasens, D. (1999). "Lingual coarticulation," Coarticulation, edited by W. J. Hardcastle and N. Hewlett Cambridge University Press, Cambridge, pp. 80-104.

Sindusha, C., Irfana, M., \& Sreedevi, N. (2014). Crosslinguistic comparison of angle of retroflection and area of retroflection using ultrasound imaging. Proceedings of Frontiers in Research of Speech and Music, Mysore.

Stevens, K. N., \& House, A. S. (1963). Perturbation of vowel articulations by consonantal context: An acoustical study. Journal of Speech and Hearing Research, 6, 111-128.

Yeou, M. (1995). Trading relations between cues for the pharyngealized/ non-pharyngealized contrast. 13th International Conference of Physical Science. 464-467.

Zharkova, N. (2008). An Investigation of Coarticulation Resistance in Speech Production Using Ultrasound. PhD thesis, Queen Margaret University, Edinburgh. 